\title{
Factors Influencing the Development of Urothelial Lesions and Breast Tuberculosis among Pulmonary TB Patients Undergoing Directly Observed Therapy in Abeokuta and Ilishan Metropolises, Ogun State, Nigeria
}

\author{
Jude Ogechukwu Okoye ${ }^{1, *}$, Precious Enyinnaya Okorie ${ }^{1}$, Nnodimele Onuigbo Atulomah ${ }^{2}$, \\ Folahan Sholeye ${ }^{3}$, Ukpai Agwu Eze ${ }^{4}$, Esther Chinenye Okoro ${ }^{5}$, Gideon Taiwo Faloye ${ }^{1}$ \\ ${ }^{1}$ Histopathology/Cytopathology Unit, Medical Laboratory Science Department, School of Public and Allied Health, Babcock University, \\ Ilishan-Remo, Nigeria \\ ${ }^{2}$ Department of Public Health, School of Public and Allied Health, Babcock University, Nigeria \\ ${ }^{3}$ Community Medicine Department, Olabisi Onabanjo University Teaching Hospital, Shagamu, Nigeria \\ ${ }^{4}$ Molecular Biosciences and Medical Microbiology Division, Department of Medical Laboratory Sciences, Faculty of Health Sciences and \\ Technology, Ebonyi State University, Nigeria \\ ${ }^{5}$ Virology Unit, Medical Laboratory Services, Enugu State University Teaching Hospital, Nigeria
}

Copyright $(2016$ by authors, all rights reserved. Authors agree that this article remains permanently open access under the terms of the Creative Commons Attribution License 4.0 International License

\begin{abstract}
This questionnaire-laboratory based cohort study evaluated some socio-demographic characteristics and urothelial integrity among pulmonary tuberculosis (TB) patients. A total of 49 confirmed TB positive patients (males $=17$ and females $=32$ ) within the age range of 10-79 years were recruited from Abeokuta and Ilishan metropolises, and divided into 2 groups: patients on anti-TB drugs and those not on anti-TB drugs. Smears made using cell deposits from fresh clean catch urine samples were stained by the Papanicolaou and Giemsa techniques. In this study, high frequency of TB infection was associated with gender, ethnicity, residency, marital status, occupation, and income status. The prevalence of urothelial lesion and breast tuberculosis was $24.5 \%$ and $8.2 \%$, respectively with high frequency among patients within the age range of 30 to 39 years. A significant difference between patients on anti-TB drugs and those not on anti-TB drugs was observed in relation to low grade urothelial lesions $(\mathrm{p}<0.05)$. Subgroup comparison showed that approximately $47 \%, 45 \%, 34 \%$ and $17 \%$ of the urothelial lesions were associated with lack of TB therapy, HIV and TB co-infection, females and breast tuberculosis, respectively when compared with other subgroups. Interestingly, polyomavirus (45\%), HIV (43\%) fungal infections $(39 \%)$, parasites $(24 \%)$ and crystals $(18 \%)$ were associated with the urothelial lesions $(\mathrm{p}<0.05)$. This study suggests that lack of TB therapy, age, female-sex and some co-infections may increase the risk of urothelial lesions and breast tuberculosis. Thus, female patients living in TB endemic areas and within the age range of 30 to 59 years should be screened pre- and post treatment.
\end{abstract}

Keywords Mycobacterium tuberculosis, Breast Tuberculosis, Urothelial Lesions, Polyomavirus, HIV, Parasites

\section{Introduction}

Tuberculosis (TB) is still a leading cause of death, especially in underdeveloped and developing countries and transmitted through droplet aerosolization by an individual with active pulmonary disease [1]. The risk of an individual progressing from latent infection to active disease (reactivation) depends on the bacterial load and the effectiveness of their immune defenses [2]. According to the World Health Organization (WHO), more than 2 billion people, equal to one-third of the world's population, are currently infected with tuberculosis bacilli with 9.2 million new cases and 1.7 million deaths TB in 2006 [3]. In Nigeria, TB death rates declined from $11 \%$ in 2006 to $5 \%$ in 2010 but have since increased [4]. Nigeria ranked eleventh among the 22 high-burden countries in the world in 2013, with a total of 180,000 cases occurring annually [5]. Interestingly, in 2014, WHO ranked Nigeria as the $3^{\text {rd }}$ country among the 22 countries with the highest prevalence of $\mathrm{TB}$, with 600,000 new cases [6]. The burden of cancer is increasing globally, with an expected 20 million new cases in 2020, half of which will be in the low-and middle-income countries [7]. With the increasing prevalence of TB cases in Nigeria, the incidence of bladder cancer, urothelial carcinoma or lesions among 
these TB patients may also be on the rise. The incidence of TB increases with age and is two to three times higher in men than in women of the same age [8,9]. Most often the lung is affected, but, after lymphadenopathy, the most common form of non-pulmonary tuberculosis is genitourinary disease, accounting for $27 \%$ to $41 \%$ of non-pulmonary cases in several surveys in the United States, Canada, and United Kingdom [10]. Urinary TB (UTB) is a relatively common form of extra-pulmonary TB, constituting 3 to $5 \%$ of all TB cases [11]. Cancer in TB patients is believed to be caused by the bacterial activity. Leukemias and lymphomas are mainly associated with mycobacterial reinfections $[12,13]$. Bladder cancer is an important worldwide health problem with a global estimate of 386,300 new cases and 150,200 deaths in the year 2008. Delays in TB diagnosis and in the initiation of anti-TB treatment have been reported to increase the duration and severity of urinary tract inflammation, urinary tract scaring, obstructive uropathy and organ fibrosis, thus making the patient more vulnerable to urinary tract cancer $[14,15]$. The aim of this study was to evaluate the integrity of urothelial cells in relation to some sociodemographic characteristics.

\section{Materials and Methods}

\subsection{Study Area, Population and Design}

Primary health centres in Abeokuta (Latitude $07^{\circ} 03^{\prime} \mathrm{N}$ and Longitude $03^{0} 19^{\prime} \mathrm{E}$ ) and Ilishan (Latitude $06^{\circ} 53 \mathrm{~N}$ and longitude $03^{0} 42 \mathrm{E}$ ) in Ogun State [16], were used as recruitment centres for this cohort study. A total of 49 patients were consecutively recruited (between the months of May and June, 2016) and categorized into two groups: TB patients on anti-TB drug (Group 1) and TB patients not on anti-TB drugs (Group 2).

\subsection{Inclusion and Exclusion Criteria}

TB positive patients (confirmed by sputum culture, clinical symptoms and radiological evidence suggestive of TB) and within the age range of 10-79 years were included in this study [17]. Patients who were diabetic, menstruating, had had organ transplant, catheterized or have been diagnosed of any other cancer other than urinary tract cancer were excluded from this study.

\subsection{Ethical Approval}

Ethical clearances were obtained from the Ethics Committees of Babcock University Health Research (BUHREC344/16) and State Hospital Abeokuta (SHA/RES/VOL.1/015) for this research work. Written informed consents were obtained from the participants following prior explanation of the aim and whole procedure of the study.

\subsection{Collection and Staining of Cytological Smears}

Freshly voided, clean catch urine samples were collected in sterile containers from the patients and transported to the laboratory complex at Babcock University for centrifugation and smearing of cell deposits. Smears were stained using the Papanicolaou and Giemsa staining techniques $[18,19]$.

\subsection{Classification of Smears}

Smears were classified from negative for urothelial lesion to high grade lesion based on the following criteria: Low-grade papillary urothelial carcinoma/lesion is characterized by an overall orderly appearance, cohesion, minimal variability in architectures, and lack of significant cytologic atypia and mitotic activity [20,21]. The nuclei of low grade papillary urothelial lesion are enlarged, elongated and oval or round with fine chromatin with conspicuous nucleoli [22]. In contrast, high grade urothelial carcinoma/lesion is characterized by a disorderly appearance with marked architectural and cytologic atypia, which are recognizable at low magnification. There is increased nuclear/cytoplasmic ratio, hyperchromasia, cell discohesion, anisocytosis, pleomorphism, frequently coarse chromatin, prominent single to multiple and mitotic nucleoli [22]. Smears which do not possess sufficient characteristics as seen in low and high grade lesion were classified as been negative for urothelial lesion.

\subsection{Statistical Analysis}

Statistical analyses involving frequency distribution, paired sample t-test and paired sample correlation test were carried out to investigate the relationship between sociodemographic characteristics, anti-TB-drugs administration and some cytological laboratory findings. The level of significance was set at $p<0.05$ (using SPSS version 20.0).

\section{Result}

Table 1 shows higher prevalence of TB infection among females, Christians, rural dwellers, patients from monogamous families, low income earners, sexually active, Yoruba and Self-employed patients, married, and patients without a university degree (but most prevalent among those with secondary school education) compared with other subgroups. More so, high frequencies of breast lump, sexual activeness, and urogenital infection were observed among females compared with the male sero-positive patients, while high frequencies of smoking, genital ulcer and alcohol intake were observed among males compared with the females. Approximately eighteen percent (18\%) of the patients appear to have been infected for over 6 months, hence the over 6 month's duration of cough. More so, approximately $6 \%$ of cough presentations (among those who have been receiving treatment for greater than 7 months) appear to be resistant. The duration of infection and resistance to therapy may have increased the chance of extra-pulmonary tuberculosis. 
Table 1. Distribution of socio-demographic and life-style characteristics among TB infected patients

\begin{tabular}{|c|c|c|c|c|c|}
\hline \multirow{2}{*}{$\begin{array}{c}\text { Characteristics } \\
\text { Gender/Sex: }\end{array}$} & \multicolumn{5}{|c|}{ Frequency distribution across the groups (\%) } \\
\hline & Male $=17(34.70)$ & Female $=32(65.30)$ & & & \\
\hline Smokers: & Yes $=7(14.30)$ & $\mathrm{No}=42(85.70)$ & Male $=6 / 7$ & Female $=1 / 7$ & \\
\hline Alcohol intake: & Yes $=12(24.50)$ & $\mathrm{No}=37(75.50)$ & Male $=8 / 12$ & Female $=4 / 12$ & \\
\hline Social drugs: & Yes $=1(2.00)$ & $\mathrm{No}=48(98.00)$ & Male $=1 / 1$ & Female $=0 / 1$ & \\
\hline Sexual activeness: & Yes $=34(69.4)$ & $\mathrm{No}=15(30.6)$ & Male $=12 / 34$ & Female $=22 / 34$ & \\
\hline $\begin{array}{l}\text { Urogenital } \\
\text { Infection: }\end{array}$ & Yes $=6(12.2)$ & $\mathrm{No}=43(87.8)$ & Male $=2 / 6$ & Female $=4 / 6$ & \\
\hline Genital Ulcer: & $\mathrm{Yes}=3(6.1)$ & $\mathrm{No}=46(93.9)$ & Male $=3 / 3$ & Female $=0 / 3$ & \\
\hline Breast lump: & Yes $=4(8.2)$ & $\mathrm{No}=45(91.8)$ & Male $=0 / 4$ & Female $=4 / 4$ & \\
\hline Residency: & Urban $=16(32.70)$ & & Rural $=33(67.30)$ & & \\
\hline Family type: & Polygamous $=20(40$. & & Monogamous $=29(59.20$ & & \\
\hline Religion: & Christianity $=31(63.3$ & & Islam $=16(32.70)$ & Others: $2(4.10)$ & \\
\hline Income Status: & Low $=28(57.10)$ & Middle $=18(36.70)$ & $\mathrm{High}=3(6.10)$ & & \\
\hline Duration of cough: & $\begin{array}{l}0 \text { to } 1 \text { month }=16 \\
(32.70)\end{array}$ & $\begin{array}{l}2-6 \text { months }=18 \\
(36.70)\end{array}$ & $\begin{array}{l}7 \text { months }-1 \text { year }=13 \\
(26.70)\end{array}$ & $\begin{array}{l}>1 \text { year }=2 \\
(4.10)\end{array}$ & \\
\hline $\begin{array}{l}\text { Anti-TB drug } \\
\text { intake: }\end{array}$ & $\mathrm{Yes}=30(61.22)$ & $\mathrm{No}=19(38.78)$ & Male $=14 / 30$ & Female $=16 / 30$ & \\
\hline Duration of $\mathrm{TB} \mathrm{Tt}$ & 0 time $=19(38.78)$ & $\begin{array}{l}1-6 \text { months }=27 \\
(55.10)\end{array}$ & $\begin{array}{l}7 \text { months }-1 \text { year }=2 \\
(4.08)\end{array}$ & $>1$ year $=1(2.04)$ & \\
\hline Tribe/Ethnicity: & Igbo $=10(20.40)$ & Yoruba $=36(73.5)$ & Hausa $=0(0.00)$ & Others $=3(6.10)$ & \\
\hline Occupation: & Student $=8(16.30)$ & $\begin{array}{l}\text { Self employed }=31 \\
(63.30)\end{array}$ & Civil Servant= 8 (16.30) & $\begin{array}{l}\text { Unemployment=2 } \\
(4.10)\end{array}$ & \\
\hline Marital Status: & Single $=11(22.40)$ & Married $=35(71.40)$ & Divorced $=0(0.00)$ & Separated $=1(2.00)$ & Widowed $=2(4.10)$ \\
\hline Education level: & $\mathrm{NFE}=12(24.50)$ & Primary= 7 (14.30) & Secondary= $14(28.60)$ & C.E $=11(22.40)$ & University $=5(10.20)$ \\
\hline
\end{tabular}

Keys: $\mathrm{Tt}=$ treatment, $\mathrm{NFE}=$ No formal education, $\mathrm{C} . \mathrm{E}=$ College of education, $\mathrm{TB}=$ Tuberculosis, $\mathrm{N}=49$

Table 2. Correlation between so socio-demographic factors and clinical findings among TB patients

\begin{tabular}{cccc} 
Parameters & r-value & P-value & Relationship \\
\hline Alcohol vs Smoking & 0.717 & 0.000 & Direct \\
Alcohol vs gender & 0.383 & 0.007 & Direct \\
$\begin{array}{c}\text { Smoking vs gender } \\
\text { Sexual activeness and } \\
\text { gender }\end{array}$ & 0.315 & 0.027 & Direct \\
$\begin{array}{c}\text { Genital ulcer vs gender } \\
\text { Genital ulcer vs Urogenital } \\
\text { infection }\end{array}$ & 0.298 & 0.038 & Direct \\
$\begin{array}{c}\text { Genital ulcer vs age } \\
\text { Breast lump vs income } \\
\text { status }\end{array}$ & -0.351 & 0.013 & Inverse \\
$\begin{array}{c}\text { Duration of Cough vs } \\
\text { income status }\end{array}$ & -0.371 & 0.009 & Inverse \\
$\begin{array}{c}\text { Anti-TB drugs vs Breast } \\
\text { lump }\end{array}$ & -0.315 & 0.008 & Inverse \\
$\begin{array}{c}\text { Anti-TB drug intake vs } \\
\text { urogenital infection }\end{array}$ & -0.342 & 0.016 & Inverse \\
$\begin{array}{c}\text { Anti-TB drug intake vs } \\
\text { genital ulcer }\end{array}$ & -0.342 & 0.016 & Inverse \\
\hline
\end{tabular}

$\mathrm{N}=49$, $\mathrm{P}$-value is significant at $<0.05$. Paired sample correlation test
The inverse relationships between duration of cough, breast lumps and income status $(\mathrm{p}<0.05)$ observed in table 2 above suggest that the lower the income status, the higher the frequency of breast lumps and increased duration of cough. The inverse relationship between anti-TB drugs, breast lump, urogenital infection and ulcer genital $(\mathrm{p}<0.05)$, suggests that lack of TB therapy among the infected patients may have lead to extra-pulmonary manifestation. The inverse relationship between age and genital ulcer $(\mathrm{p}<0.05)$ indicates that the frequency of the observed genital ulcer decreases with age. More so, direct relationship between urogenital infection and genital ulcer $(\mathrm{p}<0.05)$ indicates that some of the patients who had urogenital infection also had genital ulcers. The correlation between gender and sexual activeness, and gender and genital ulcer $(p<0.05)$ indicates that there were more sexually active female in this study than males while males had high frequency of genital ulcer compared with their female counterparts. The direct relationship between gender, smoking and alcohol intake $(p<0.05)$ suggests that these habits were more frequent in males compared with their female counterparts. 
Table 3. Relationship between age, lesion and BT among TB patients

\begin{tabular}{|c|c|c|c|c|c|c|c|c|}
\hline Age range & $\begin{array}{c}\text { №P }(\%) \\
N=49 \\
\end{array}$ & $\begin{array}{c}\text { Males } \\
\mathrm{n}=17\end{array}$ & $\begin{array}{c}\text { Female } \\
\mathrm{n}=32\end{array}$ & $\begin{array}{c}\operatorname{LGL}(\%) \\
\mathrm{n}^{1}=10\end{array}$ & $\begin{array}{c}\text { HGL }(\%) \\
n^{2}=2\end{array}$ & $\begin{array}{c}\text { BT (\%) } \\
n^{3}=4 \\
\end{array}$ & $\begin{array}{c}\mathrm{LGL}+\mathrm{BT}(\%) \\
\mathrm{n}^{4}=1\end{array}$ & $\begin{array}{c}\mathrm{HGL}+\mathrm{BT}(\%) \\
\mathrm{n}^{5}=1\end{array}$ \\
\hline $10-19 y r s$ & $4(08.16)$ & $3(17.65)$ & $1(03.13)$ & 0 & 0 & 0 & 0 & 0 \\
\hline $20-29 y r s$ & $5(10.20)$ & $0(00.00)$ & $5(15.63)$ & $2(30.00)$ & 0 & 0 & 0 & 0 \\
\hline $30-39 y r s$ & $19(38.78)$ & $6(35.29)$ & $13(40.63)$ & $4(30.53)$ & $2(55.27)$ & $2(30.27)$ & $1(58.34)$ & $1(58.34)$ \\
\hline $40-49 y r s$ & $6(12.24)$ & $2(11.76)$ & $4(12.50)$ & $1(13.34)$ & 0 & $1(20.84)$ & 0 & 0 \\
\hline $50-59 y \mathrm{yrs}$ & $8(16.33)$ & $2(11.76)$ & $6(18.75)$ & $3(33.75)$ & 0 & $1(20.84)$ & 0 & 0 \\
\hline $60-69 y \mathrm{yrs}$ & $6(12.24)$ & $4(23.53)$ & $2(06.25)$ & 0 & 0 & 0 & 0 & 0 \\
\hline 70-79yrs & $1(02.04)$ & $0(00.00)$ & $1(03.13)$ & 0 & 0 & 0 & 0 & 0 \\
\hline
\end{tabular}

Keys: №P= Number of patients, $\mathrm{LGL}=$ Low grade lesion, $\mathrm{HGL}=$ High grade lesion, $\mathrm{BT}=$ Breast tuberculosis, $\mathrm{n}^{1} \%=$ Number of patients with $\mathrm{LGL}$ within the age range against the total number of patients with LGL (10) in percentage, $\mathrm{n}^{2} \%=$ Number of patients with HGL within the age range against the total number of patients with HGL (2) in percentage, $\mathrm{n}^{3} \%=$ Number of patients with BT within the age range against the total number of patients with BT in percentage, $\mathrm{n}^{4} \%=$ Number of patients with LGL plus BT within the age range against the total number of patients with LGL plus BT in percentage, $\mathrm{n}^{5} \%=$ Number of patients with HGL plus BT within the age range against the total number of patients with HGL plus BT in percentage.

The table 3 above shows an undulating frequency pattern and descending prevalence of TB and low grade lesions within the age range of 30 to 39,20 to 29,50 to 59 and 40 to 49 years. However, high grade lesions were only observed among patients within the age range of 30-39 years while high frequency of breast tuberculosis was observed among those within the age range of 30 to 39 years compared with those within the age range of 40 to 59 years. The table also shows high prevalence of TB and urothelial lesions among females compared with their male counterparts. Thus, this table suggests that females within the age range of 30 to 39 years are at higher risk of extra-pulmonary tuberculosis and cytopathic changes.

Table 4. Frequency and relationship between the laboratory findings among TB patients

\begin{tabular}{|c|c|c|c|c|c|c|c|c|c|c|c|c|}
\hline $\begin{array}{l}\text { Parameters } \\
\text { (P) }\end{array}$ & $\begin{array}{c}\text { №PA } \\
(\%)\end{array}$ & POD & PNOD & $\begin{array}{c}\text { POD VS } \\
\text { PNOD } \\
P \text {-value }\end{array}$ & $\begin{array}{l}\text { Males } \\
(\mathrm{M})\end{array}$ & $\begin{array}{c}\text { Females } \\
(\mathrm{F})\end{array}$ & $\begin{array}{l}\text { M VS F } \\
p \text {-value }\end{array}$ & LGL & HGL & $\begin{array}{c}\mathrm{UL} \\
\left(\mathrm{n}^{6} \%\right)\end{array}$ & $\begin{array}{c}\text { P Cor. } \\
\text { UL } \\
\text { r-value }\end{array}$ & $\begin{array}{c}\text { P Cor. } \\
\text { UL } \\
p \text {-value } \\
\end{array}$ \\
\hline Haematuria & $8(16.33)$ & 5 & 3 & 0.159 & 3 & 5 & 0.159 & 4 & 2 & $6(62.50)$ & 0.846 & $0.000^{*}$ \\
\hline Fungi & $9(18.37)$ & 7 & 2 & $0.024 *$ & 2 & 7 & $0.024 *$ & 3 & 1 & $4(38.89)$ & 0.629 & $0.000^{*}$ \\
\hline Crystals & $\begin{array}{c}10 \\
(20.40)\end{array}$ & 8 & 2 & $0.013^{*}$ & 6 & 4 & 0.159 & 2 & 0 & $2(18.34)$ & 0.407 & $0.004 *$ \\
\hline Decoy cells & $4(8.16)$ & 3 & 1 & 0.322 & 0 & 4 & 0.044 & 2 & 1 & $3(45.00)$ & 0.857 & $0.000^{*}$ \\
\hline HIV & $\begin{array}{c}11 \\
(22.45)\end{array}$ & 6 & 5 & 0.322 & 1 & 10 & $0.002 *$ & 4 & 1 & $5(43.56)$ & 0.627 & 0.000 * \\
\hline Parasites & $6(12.24)$ & 2 & 4 & 0.159 & 2 & 4 & 0.159 & 2 & 0 & $2(24.75)$ & 0.552 & $0.000^{*}$ \\
\hline LGL & $\begin{array}{c}10 \\
(20.41)\end{array}$ & 3 & 7 & $0.044^{*}$ & 1 & 9 & $0.004 *$ & - & - & - & & \\
\hline HGL & $2(4.08)$ & 0 & 2 & 0.159 & 0 & 2 & 0.159 & - & - & - & & \\
\hline
\end{tabular}

Keys: Cor. $=$ Correlation, №PA $=$ number of patients affected, $\mathrm{POD}=$ patients on anti-TB drugs, $\mathrm{PNOD}=$ patients not on anti-TB drugs, $\mathrm{VS}=\mathrm{versus}, \mathrm{LGL}=$ Low grade lesion, $\mathrm{HGL}=\mathrm{High}$ grade lesion, $\mathrm{UL}=$ Urothelial lesion (LGL plus HGL), $\mathrm{n}^{6} \%=$ Number of parameter in association with UL against the total number of identified parameter plus number of UL associated with laboratory parameter against the total number of UL divided by 2 . P-value is significant at $\mathrm{p}<0.05$. Paired sample T-test (POD VS PNOD and M VS F), Paired sample correlation test (P VS UL).

Table 4 above shows that there are significant differences in the presence of fungal infection, crystals and low grade lesion when those patients on anti-TB drugs were compared with those not on anti-TB drug $(p<0.05)$. Significant differences in the presence of fungi infection, polyomavirus, parasites and low grade lesion were also observed when male patients were compared with their female counterparts $(\mathrm{p}<0.05$ and 0.01$)$. Furthermore, significant correlations between the laboratory parameters (findings) and urothelial lesions $(\mathrm{p}<0.01)$ were also observed. 


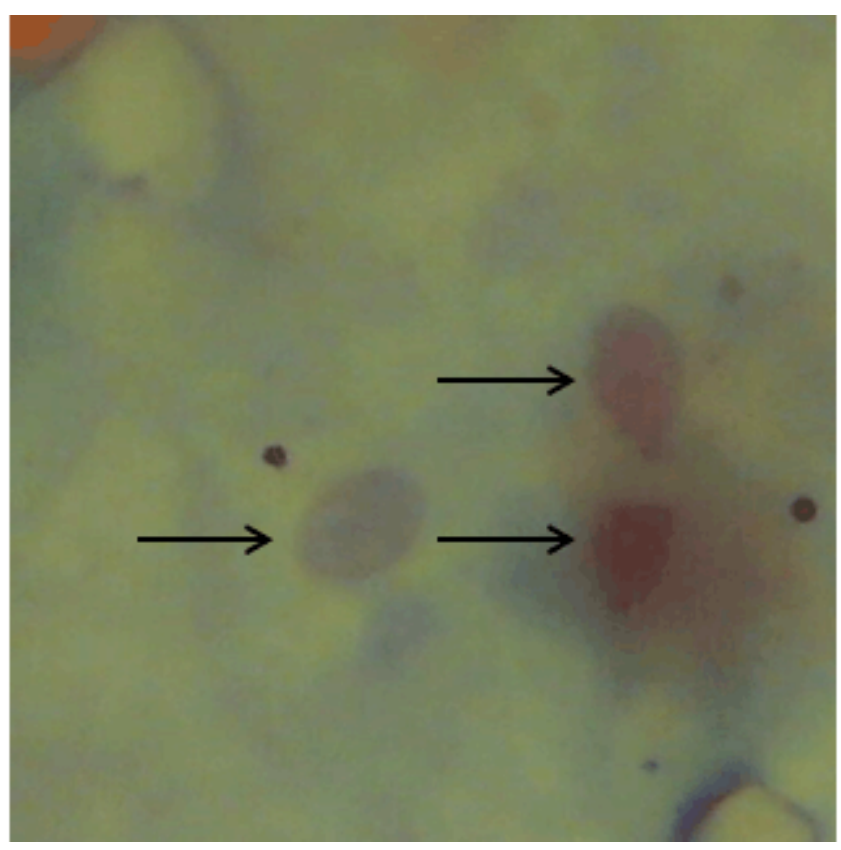

Figure 1. Photomicrograph of atypical umbrella cells with increased pleomorphic nuclei and conspicious-suggestive of high grade lesion (Giemsa Stain, X400).

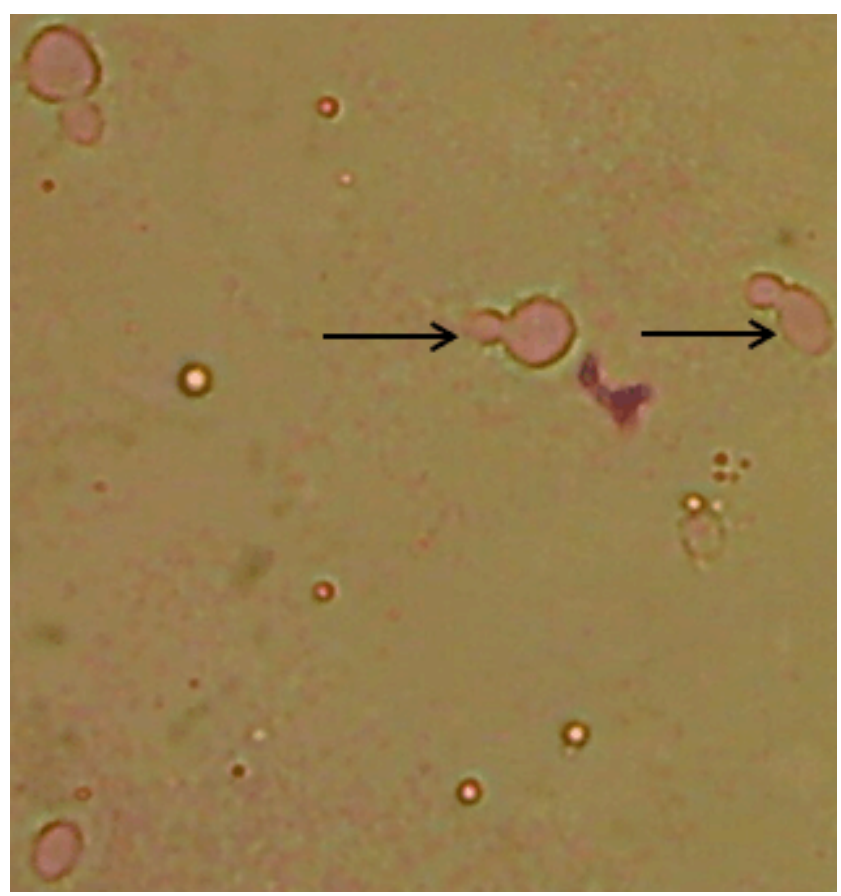

Figure 2. Photomicrograph of budding yeast cells in voided urine deposit (marked by arrows) an evidence of bladder Candidiasis. (Papanicolaou stain, $\mathrm{X} 400)$.

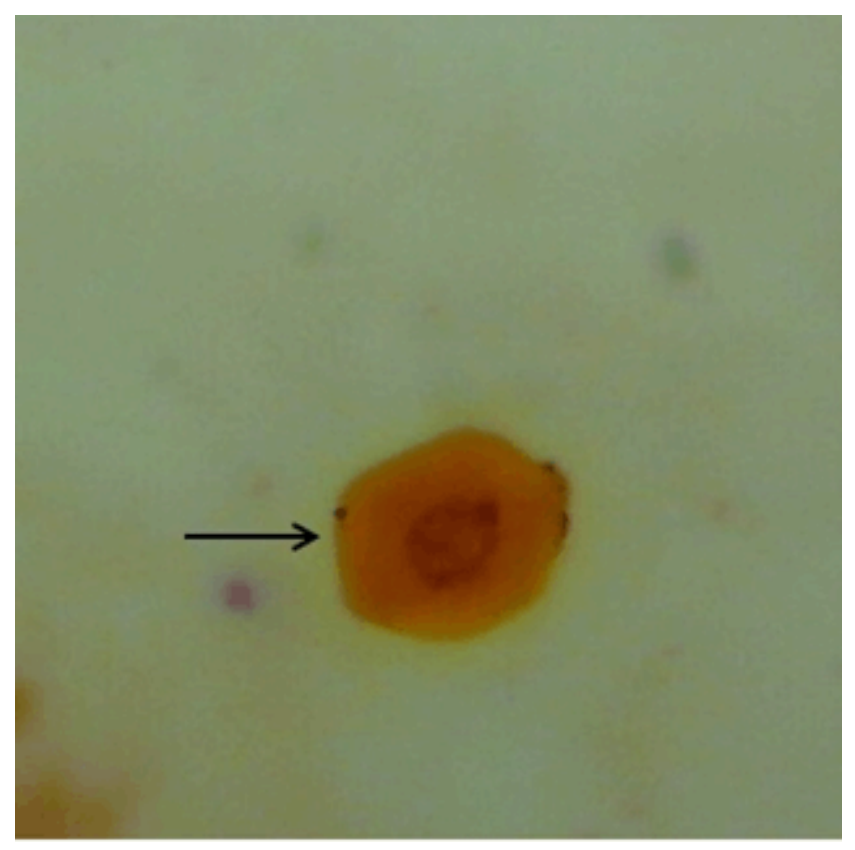

Figure 3. Photomicrograph of a urothelial cell with increased nuclear/cytoplasmic ratio and keratinization (Giemsa stain, $\mathrm{X} 400)$.

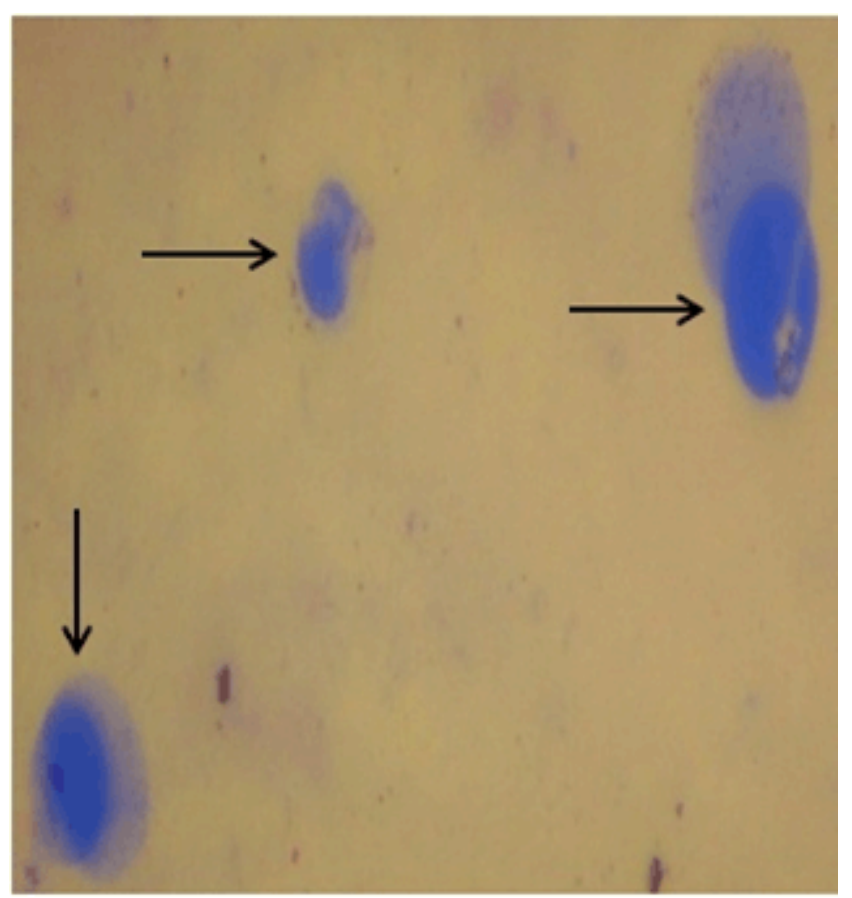

Figure 4. Photomicrograph of classical decoy cells with round, smooth, enlarged, eccentrically placed and hyperchromatic nuclei- indicative of Polyoma (BK) virus infection (Giemsa stain, X400). 


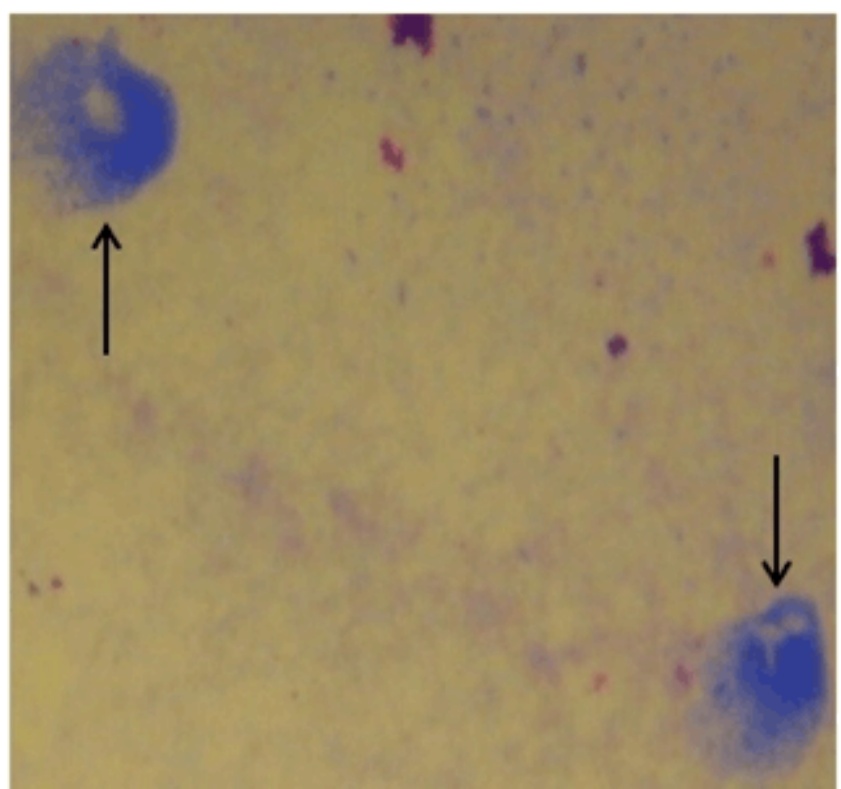

Figure 5. Photomicrograph of atypical decoy cells with eccentrically placed nuclei and evidence of anisokaryosis (Giemsa stain, X400).

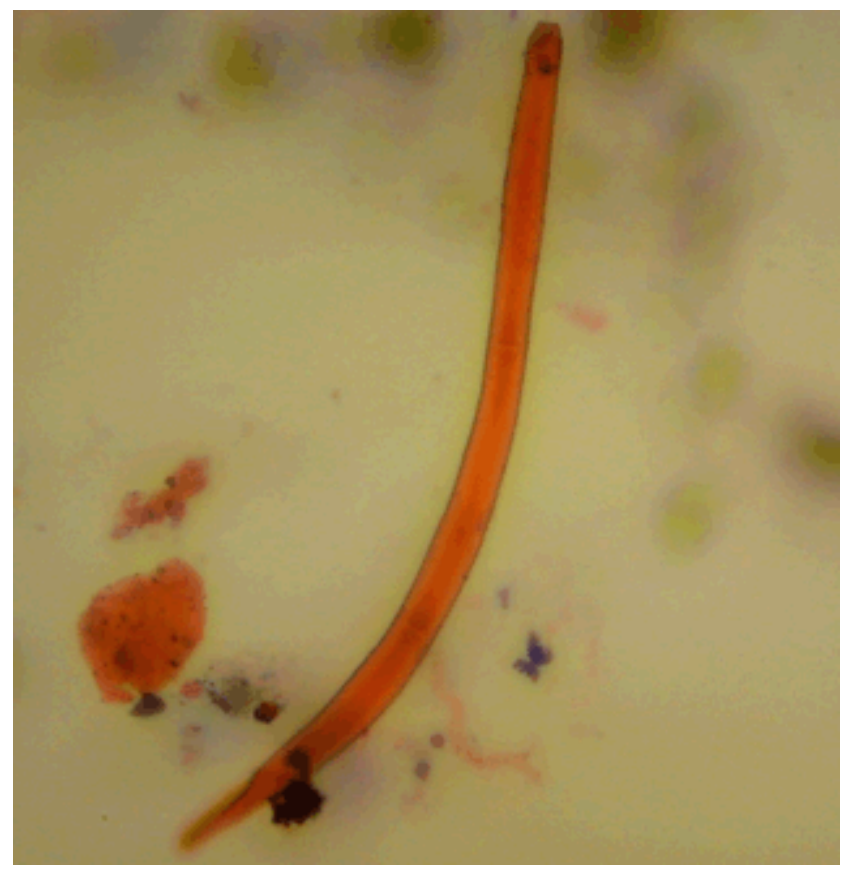

Figure 6. Photomicrograph of a Pinworm (Enterobius vermicularis) (Papanicolaou stain, X400).

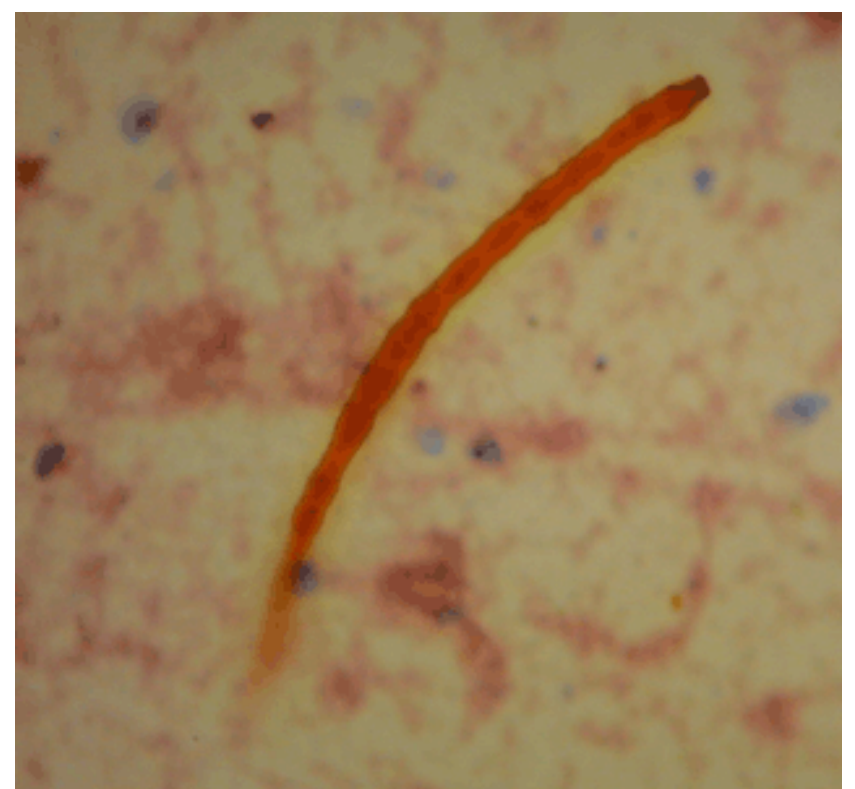

Figure 7. Photomicrograph of Enterobius gregorii (Papanicolaou stain, $\mathrm{X} 400)$.

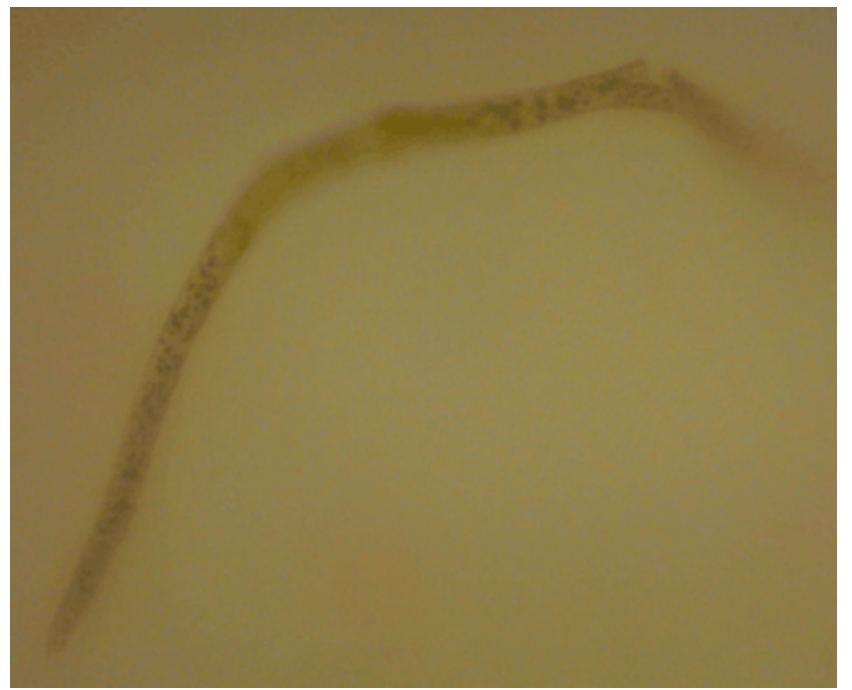

Figure 8. Photomicrograph of juvenile Onchocerca volvulus (Papanicolaou stain, X400).

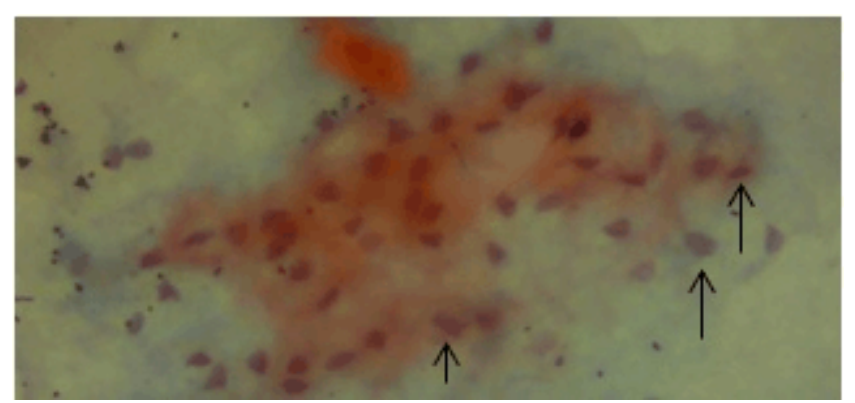

Figure 9. Photomicrograph of a progressive high grade lesion (umbrella cells) with elongated nuclei, pleomorphism, hyperchromasia, hyperkeratinization and crowding of umbrella cells with evidence of increased mitotic figures (Papanicolaou stain, X200). 


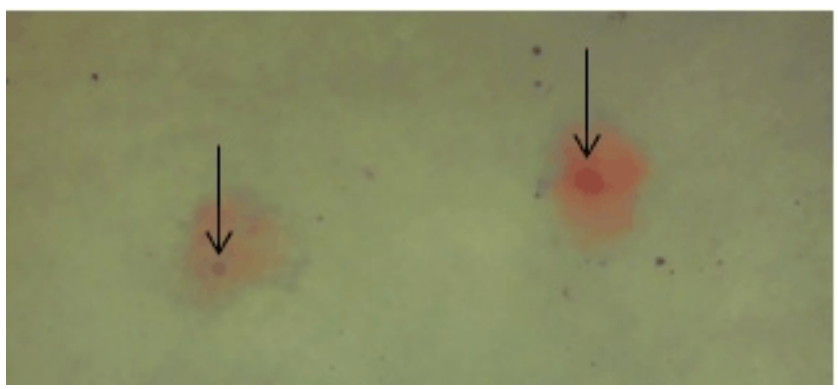

Figure 10. Photomicrograph of pleomorphic and keratinized umbrella cells suggestive of low grade lesion (Papanicolaou stain, X200).

\section{Discussion}

\subsection{Socio-demographic Factors among TB Patients}

In literature, reports of TB are higher among men than among women in a ratio of $2: 1$, probably due to drug use, alcohol intake, smoking habit, occupation, physiological and anatomical factors $[23,24]$. This is contrary to our findings which showed a female to male prevalence ratio of 1.85 (tables 1). This variation may be adduced to ethnicity and culture, as more TB notifications were observed among patients from the Yoruba tribe compared with patients of other tribes (table 1). However, the genetic link between ethnicity and TB infectivity is still unclear. The prevalent low income status (less than 18,000 Naira per month) revealed by this study may be due to poor economy and lack of government provided jobs (which provides the minimum wage for workers), hence the high rate of self-employment among the recruited participants (table 1). This is in line with previous reports in literature which suggest that there is concordance between TB prevalence and poverty [25]. In this study, notification of TB infection was higher among individuals living in rural areas compared with those living in urban areas (table 1). This could be adduced to the poor living condition and low access to health services in rural communities as against those seen in urban communities [26]. Furthermore, organizations or institutions that pay the acceptable minimum wage as stated by law are hardly found in rural settings, hence the high frequency of low income earners (self-employed) in rural communities (table 1). This low income earners may not afford a balanced diet, thus they are at a higher risk of being malnourished and having low immune status. This may be the reason for the high notification of TB infection in rural compared with urban communities in this study. It also explains the negative correlation between duration of cough and income status (the higher the income status, the shorter duration of cough due to good nutrition and better immunocompetence). Tuberculosis may be expected to be high among polygamous families as more contact will be made in such setting; however this study showed high TB infection among the married and monogamous families compared to their counterparts. Religion appears to play an independent role in $\mathrm{TB}$ prevalence in this study because the observed high prevalence of TB infected Christians compared with other religion may be due to the higher number of Christians in Ogun state. Anti-TB drug resistance and longer duration of TB infection (indicated by longer duration of cough; table 1) may have increased the risk of extrapulmonary tuberculosis (urogenital and breast tuberculosis) among the recruited patients.

\subsection{Clinical and Laboratory Findings among TB Patients}

In chronic inflammation, the urinary tract mucosa lined by urothelial cells is predisposed to cell metaplasia, dysplasia and urinary tract cancer [27,28]. Evidence suggests that $M$. tuberculosis can induce DNA damage by the production of nitric oxide and reactive oxygen species which can result in cancer $[5,29]$. Urinary tuberculosis which has a strong association with urothelial carcinoma is typically diagnosed in elderly individuals, with a median age of 69-71 years $[8,15,30,31]$ and is associated with male sex and exogenous and environmental risk factors such as chemical carcinogens, cigarette smoking, arsenic, medications [32-37]. Its incidence increases with age and is two to three times higher in men than in women of the same age [8,9]. Contrary to the latter reports, this study showed that females had higher prevalence of urothelial lesions compared with their male counterparts (Tables 3 and 4). This is in consonance with the studies carried out in Taiwan, where the percentage of female patients with bladder cancer is higher compared with males [38,39]. The higher cases of haematuria associated with urothelial lesions observed among female TB infected patients (table 4) further lends support to the fact that females have increased risk of developing urothelial lesions compared with their male counterparts. This is consonance with the findings of Chin et al. [40] Since the number of female smokers was quite low in this study compared with their male counterparts (table 1), life-style may not have contributed to the urothelial lesions among them.

Female patients with urothelial lesions are associated with worse outcome than male patients, probably because female patients are more likely to have aggressive histology and urogenital infections at initial presentation [41-43]. The latter report is in accordance with our finding which showed that high grade lesions (figures 1 and 9) were only seen among the female TB patients who were not on anti-TB drugs and had history of urogenital infections and ulcer. It is imperative to say, though hypothetical, that female patients not on anti-TB drugs have poorer outcome when compared with their male counterparts. The direct relationship between gender and urogenital tract infection (table 2) suggest that TB infection increases the risk of urogenital tract infection among females. Only males who were not on TB treatment had genital ulcer; one of which had both genital ulcer and low grade urothelial lesion (figure 3). This is concordance with earlier reports that patients with genital and urethral TB present superficial tuberculous ulcer on the penis secondary 
to mycobacteria exposure during intercourse [11]. Thus, the inverse relationship between genital ulcer and anti-TB drug (table 2) suggests that anti-TB drug reduces the risk of genital ulcer due to the fact that it reduces the mycobacterial load. The strong positive significant correlations between urothelial lesion and other laboratory findings (table 4) suggest that $\mathrm{TB}$ is not the sole contributor to the manifestation of urothelial lesion.

\subsection{Cytopathic Changes following HIV and TB Co-infection}

In the majority of adult patients, TB is confined preferentially to the lungs, but with HIV co-infection, TB can be a systemic disease involving multiple organs that lack well-defined granulomas and instead develop more diffuse lesions which is termed extrapulmonary TB [44]. Mycobacterium tuberculosis and HIV act in synergy, accelerating the decline of immunological functions and leading to subsequent death if untreated [45]. In this study, two HIV and TB co-infected patients had both breast tuberculosis and urothelial lesion. One of the patients had low (figure 10) grade lesion and breast tuberculosis while the other had breast tuberculosis and high grade lesion. Both cases are suggestive of extra-pulmonary TB following continual decrease in immunocompetence induced by both TB and HIV.

Tuberculosis spreads to the breast through the lymphatic system from axillary, mediastinal or cervical lymph nodes $[46,47]$. Most commonly the disease presents as a lump in the central or the upper outer quadrant of the breast while multiple lumps are less frequent. Interestingly, twelve percent of the females (4 out of 32) in this study had breast lumps (table 1) which occurred at the upper lateral quadrant of the breast (three left and one right regions), following self-examination. The fact that there is an inverse relationship between breast lumps and anti-TB drug suggests that the mycobacterium load may be responsible for the breast lumps (tuberculosis) because the four patients were not on anti-TB treatment at the time of the diagnosis. The negative correlation between income status, breast lump and duration of cough among these patients (table 2) shows that the breast tuberculosis may be due to poor nutrition, high mycobacterial load and resistance to anti-TB drugs among the affected individuals (table 1). The decrease and further disappearance of the lumps on commencement of anti-TB therapy suggests that $M$. tuberculosis might be responsible for the breast lumps.

\subsection{Candidiasis and Epithelial Lesion}

Epidemiological studies have shown that when host defenses are compromised most candidal infections arise from an endogenous commensal strain rather than an exogenous strain $[48,49]$. In this study, females had higher fungi (yeast; figure 2) infections compared with males. This may be due to the shortness of the urethra (urinary opening) and its nearness to the genital tract in females, as disruption of vaginal normal flora may result in fungal invasion of nearby structures. Some of the observed fungi infections were associated with some of the low and high lesions seen among the investigated TB patients (table 4). McCullough et al. [50] and Barret et al. [51] postulated that the progression of non-dysplastic lesion to dysplasia is advanced by $C$. albicans by producing carcinogenic compounds, for example, $\mathrm{N}$-nitrosobenzylmethylamine (NBMA) which causes dysregulation of DNA replication and point mutations which eventually lead to oral cancer [52]. Hence, some of the observed urothelial lesions (tables 3 and 4) may be associated with candidiasis.

\subsection{Polyomavirus Infection and Urothelial Lesion}

Polyomaviruses of the BK- and JC-strains often remain latent within the transitional cell layer of the bladder, ureters and the renal pelvis as well as in tubular epithelial cells of the kidney. Slight changes in the immune status and/or an immunocompromised condition can lead to the (re)activation of latent polyomaviruses, resulting in the shedding of decoy cells which often contain polyoma-BK-viruses [53]. A high prevalence of decoy cell shedding is found majorly in patients suffering from cancer [54]. Polyomavirus of the BK strain have been reported to cause aggressive urinary bladder urothelial carcinomas with adenocarcinomatous or micropapillary differentiation [55]. In this study, four patients (8.2\%; table 4$)$ had evidence of polyomavirus infection (Figures 4 and 5). Two cases of classical decoy cells were observed in low grade lesion while atypical decoy cells were seen in a case of high grade lesion. The presence of atypical decoy cells (figure 5) is highly suggestive of urothelial neoplasm. The fact that these atypical decoy cells were observed in some low and high grade lesion samples suggests that polymavirus may influence the emergence of some of the observed urothelial lesions.

\subsection{Parasitic Infection}

In this study, six cases of parasitic infection were observed, however only two cases of low grade lesion were associated with the identified parasite (Enterobius spp. and Onchocerca volvulus; figures 6-8) among female patients who were not on anti-TB drug. These parasites may have been found as a result of the proximity between the urinary opening and the anus. According to Cheesburgh [56], the eggs of $E$. vermicularis are occasionally found in urine, especially from young girls when the eggs are washed off the external genitalia when urine is being passed. On other hand, they may have invaded the bladder or the urinary tract through the tissue. The persistent nature of parasite in the epithelium results in a chronic, low-level infection leading to non-resolving (chronic) lesion at the site of infection [57]. Impaired early immune response to parasitic infection due to CD4+ $\mathrm{T}$ cell exhaustion following chronic infection (TB or 
HIV and TB co-infection) creates a poor priming environment for memory cell activation. This continues cycle of tissue damage and chronic inflammation due to the presence of parasites may predispose patients to urothelial lesion.

\subsection{Crystals and Urothelial}

Urothelial calculi can serve as a location in which organisms can escape antibiotics (especially M. tuberculosis) and cause recurrent urinary tract infections or lesions. The crystals observed in the urine samples of the TB patients in this study include: uric acid crystals ( 2 males, 2 females), Sulfadiazine crystals (4 males, 1 female), and Calcium oxalate crystals ( 1 female patient. Though, the percentage of crystals associated urothelial lesion in this study may be low (approximately 17\%), the influence of crystals in the development of urothelial lesion cannot be entirely rule out. When crystals are deposited in the urinary tract due to therapy, they can cause inflammation, haematuria and other complications [56]. This could be the reason for the higher haematuria found among TB patients undergoing TB therapy (table 4) in this study. When Calcium oxalate crystals are found in freshly passed urine, they may indicate calculi in the urinary tract or severe chronic renal disease. Uric acid crystals can sometimes be found with calculi [56]. More so, alcohol intake found majorly among male TB patients (table 1) might be the cause of some of the observed crystals. Since some of the observed crystals may be due to the administered anti-TB drug, sufficient intake of water during treatment should be advised.

\section{Conclusions}

This study suggests that while polyomavirus, human immunodeficiency virus, fungi, parasites and crystals influence the development of urothelial lesions, the development of breast tuberculosis is influenced by age and HIV infections among TB infected patients. Unfortunately, screenings for urothelial carcinoma and breast tuberculosis among the TB infected patients are poor in this part of the continent due to lack of funds. It is important that female patients living in TB endemic areas that are within the age range of 20 to 59 years be screened for urothelial carcinoma and breast tuberculosis pre- and post treatment. This will go a long way to reducing cancer related mortality among TB patients.

\section{Acknowledgements}

Special thanks are due to the Chief Medical Director of Babcock University Teaching Hospital and Medical Director of State Hospital Abeokuta, and also the DOT Clinic staff of the respective hospitals for their technical support throughout the study.

\section{Competing Interest}

None declared.

\section{Funding}

Authors did not receive any funding for the study.

\section{Ethical issues}

Authors hereby declare that all investigations have been examined and approved by the appropriate ethics committee and have therefore been performed in accordance with the ethical standards laid down in the 1964 declaration of Helsinki.

\section{REFERENCES}

[1] L. Blanc, D. Falzon, C. Fitzpatrick, K. Floyd, I. Garcia, C. Gilpin, et al. Global Tuberculosis Control 2010. World Health Organization: Geneva, Switzerland. 2010.

[2] A. Konstantinos. Testing for tuberculosis. Australian Prescriber. 33, 12-18, 2010.

[3] World Health Organization. 2008. Available from: www.who.int/media centre/factsheets/fs297/en/index.html. Accessed on 4/04/2016.

[4] Nigerian fact sheet. Tuberculosis in Nigeria.Economic Section, United States Embassy in Nigeria. 2012. Available from:http://nigeria.usembassy.gov. Accessed on 11/1/2016.

[5] Vanguard News. Nigeria records 18000 cases of TB annually. 2014. Available from: www.vanguardngr.com/2014/03/ nigeria-record. Accessed on 09/03/2016.

[6] Guardian Newspaper.600000 new cases of TB in Nigeria. 2015. Available from: http://guardian.ng/news/600000-newcases. Accessed on: 09/03/2016.

[7] S. Sharma, M. Sharma, S. Roy, P. Kumar, and M. Bose. Mycobacterium tuberculosis induces high production of nitric oxide in coordination with production of tumour necrosis factor-alpha in patients with fresh active tuberculosis but not in MDR tuberculosis. Immunology and Cell Biology. 82, 377-382, 2004

[8] E. Scosyrev, K. Noyes, C. Feng, E. Messing. Sex and racial differences in bladder cancer presentation and mortality in the US. Cancer. 115(1), 68-74, 2009.

[9] R. Siegel, E. Ward, O. Brawley, and A. Jemal. Cancer statistics, 2011: the impact of eliminating socioeconomic and racial disparities on premature cancer deaths. CA Cancer Journal of Clinicians. 61(4), 212-236, 2011.

[10] D.H. Kennedy. Extra-pulmonary tuberculosis. In: The Biology of the Mycobacteria, Vol. III, edited by Ratledge C, Stanford JL, Grange JM, New York, Academic Press, pp 245-284. 1989 
[11] G.J. Wise, V.K. Marella. Genitourinary manifestations of tuberculosis. Urology Clinicians of North America. 30(1), 111-121, 2003.

[12] D. Karnak, O. Kayacan, and S. Beder. Reactivation of pulmonary tuberculosis in malignancy. Tumorigenesis. 88 , 251-254, 2002.

[13] F.A. Silva, J.O. Matos, F.C. de Mello, and M. Nucci. Risk factors for and attributable mortality from tuberculosis in patientswith hematologic malignances. Haematologica. 90, 1110-1115, 2005

[14] M.R. Ardalan and M.M. Shoja. Radiological findings in renal tuberculosis: a report from northwest of Iran. Saudi Journal Kidney Diseases and Transplantation. 19(1), 76-79, 2008.

[15] Y.C. Lien, J.Y. Wang, M.C. Lee, C.C. Shu, H.Y. Chen, C.H. Hsieh et al. Urinary tuberculosis is associated with the development of urothelial carcinoma but not renal cell carcinoma: a nationwide cohort study in Taiwan. British Journal of Cancer. 109, 2933-2940, 2013. Doi: $10.1038 /$ bjc. 2013.538

[16] Worldatlas. Where Is Shagamu, Abeokuta and Ilishan, Nigeria? 2015. Available from: http://www.worldatlas.com/a f/ng/og/where-is-shagamu.html. Accessed 17/04/2016.

[17] L.A. Vihrova, V.S. Pylypchuk, and G.A. Kutsyna. Open label trial of adjuvant immunotherapy with Dzherelo, Svitanok and Lizorm, in MDR-TB, XDRTBand TB/HIV co-infected patients receiving antituberculosistherapy under DOTS. Journal of Medicinal Plants Research. 1(5), 117-122. 2007

[18] G.N. Papanicolaou, and H.F. Traut. The diagnostic value of vaginal smears in carcinoma of the uterus.American Journal of Obstetrics and Gynecology. 42, 193-198, 1941.

[19] J. Ochei, and A. Kolhatkar. Medical Laboratory Science: theory and practice. 2nd Ed.Tata McGraw-Hill publishing company limited: New Delhi. p. 331-349, 2000.

[20] J.I. Epstein. The new World Health Organization/International Society of Urological Pathology (WHO/ISUP) classification for TA, T1 bladder tumors: is it an improvement? Critical Review in Oncology and Hematology. 47(2), 83-89, 2003.

[21] J.N. Eble, G. Sauter, J.I. Epstein, I.A. Sesterhenn, eds. Pathology and Genetics of Tumours of the Urinary System and Male Genital Organs. Lyon, France: IARC Press. World Health Organization Classification of Tumours; vol 10. 2004

[22] D.J. Grignon. The current classification of urothelial Neoplasms. Modern Pathology. 22, S60-S69, 2009.

[23] O. Neyrolles, L. Quintana-Murci. Sexual Inequality in Tuberculosis. PLoS Medicine. 6(12), e1000199. 2009. Doi:10.1371/journal.pmed.1000199

[24] Y. Boum, D. Atwine, P. Orikiriza, J. Assimwe, A.L. Page, J. Mwanga-Amumpaire, et al. Male Gender is independently associated with pulmonary tuberculosis among sputum and non-sputum producers people with presumptive tuberculosis in Southwestern Uganda. BMC Infectious Diseases. 14, 638, 2014. Doi:10.1186/s12879-014-0638-5

[25] J.P. Millet, A. Moreno, L. Fina, L. 1 Baño, A. Orcau, P.G. Olalla, J.A. Cayla. Factors that influence current tuberculosis epidemiology. European Spine Journal. 22 (Suppl 4), S539-S548, 2013. DOI 10.1007/s00586-012-2334-8
[26] I. Abubakar, J. P. Crofts, D. Gelb, A. Story, N. Andrews, J. M. Watson. Investigating Urban-Rural Disparities In Tuberculosis Treatment Outcome In England And Wales. Epidemiology and Infections. 136,122-127, 2008. Doi:10.1017/S0950268807008333

[27] J. Harikrishna, V. Sukaveni, D.P. Kumar, and A. Moha. Cancer and tuberculosis. Journal, Indian Academy of Clinical Medicine. 13(2), 142-144, 2011.

[28] S. Ling, X. Chang, L. Schultz, T.K. Lee, A. Chaux, L. Marchionni, G.J. Netto, D. Sidransky and D.M. Berman. An EGFR-ERK-SOX9 signaling cascade links urothelial development and regeneration to cancer. Cancer Research. 71(11), 3812-3821, 2011.

[29] J.O. Okoye, B.O. Joel, K. Onyenze. Urethelial dysplasia and desquamation associated with urinary tract infection. Universal J Microbiol Res. 4(2): 39-44. 2016.Doi: 10.13189/ujmr.2016.040201

[30] C.F. Lynch, M.B. Cohen. Urinary system. Cancer 75(Suppl 1): $316-329.1995$

[31] N.N.A. Howlader, M. Krapcho, J. Garshell, N. Neyman, S.F. Altekruse, C.L. Kosary, M. Yu, J. Ruhl, Z. Tatalovich, H. Cho, A. Mariotto, D.R. Lewis, H.S. Chen, E.J. Feuer, K.A. Cronin (eds). SEER Cancer Statistics Review 1975-2010. National Cancer Institute: Besthesda, MD, USA. 2013

[32] S.L. Johansson, S.M. Cohen. Epidemiology and etiology of bladder cancer. Semin Surg Oncol 13(5), 291-298, 1997.

[33] D. de Ridder, H. van Poppel, L. Demonty, B. D’Hooghe, R. Gonsette, H. Carton, L. Baert. Bladder cancer in patients with multiple sclerosis treated with cyclophosphamide. Journal of Urology, 159(6), 1881-1884, 1998

[34] W. Pommer, E. Bronder, A. Klimpel, U. Helmert, E. Greiser, M. Molzahn. Urothelial cancer at different tumour sites: role of smoking and habitual intake of analgesics and laxatives. Results of the Berlin Urothelial Cancer Study. Nephrology, Dialysis and Transplant. 14(12), 2892-2897, 1999.

[35] Y. Kakehi, Y. Hirao, W.J. Kim, S. Ozono, N. Masumori, N. Miyanaga, Y. Nasu and A. Yokomizo. Bladder Cancer Working Group report. Japan Journal of Clinical Oncology. 40(Suppl 1), i57-i64, 2010

[36] M.N. Lai, S.M. Wang, P.C. Chen, Y.Y. Chen and J.D. Wang. Population-based case-control study of Chinese herbal products containing aristolochic acid and urinary tract cancer risk. Journal of National Cancer Institute. 102(3), 179-186, $2010 \mathrm{~b}$

[37] R. Mamtani, K. Haynes, W.B. Bilker, D.J. Vaughn, B.L. Strom, K. Glanz, J.D. Lewis. Association between longer therapy with thiazolidinediones and risk of bladder cancer: a cohort study. Journal of National Cancer Institute. 104(18), 1411-1421, 2012

[38] Y.H. Chou and C.H. Huang. Unusual clinical presentation of upper urothelial carcinoma in Taiwan. Cancer 85(6), 1342-1344, 1999

[39] P. F. Rambau, P. L. Chalya and K. Jackson Schistosomiasis and urinary bladder cancer in North Western Tanzania: a retrospective review of 185 patients. Agents and Cancer. 8, 19,2013 
[40] S.N. Chin, T. Foster, G. Char, and A. Garrison. Concomitant Urothelial Cancer and Renal Tuberculosis. Article ID 625153. 2014. Doi.org/10.1155/2014/625153

[41] N.A. Mungan, K.K. Aben, M.P. Schoenberg, O. Visser, J.W. Coebergh, J.A. Witjes, L.A. Kiemeney. Gender differences in stage-adjusted bladder cancer survival. Urology. 55(6), 876-880, 2000

[42] K.W. Jung, S. Park, A. Shin, C.M. Oh, H.J. Kong, J.K. Jun and Y.J. Won. Do female cancer patients display better survival rates compared with males? Analysis of the Korean National Registry data, 2005-2009. PLoS One 7(12): e52457. 2012

[43] A.P. Noon, P.C. Albertsen, F. Thomas, D.J. Rosario and J.W. Catto. Competing mortality in patients diagnosed with bladder cancer: evidence of undertreatment in the elderly and female patients. Br J Cancer 108(7), 1534-1540, 2013

[44] de Noronha AL, Bafica A, Nogueira L, Barral A, Barral-Netto M (2008) Lung granulomas from Mycobacterium tuberculosis/HIV-1 co-infected patients display decreased in situ TNF production. Pathol Res Pract 204: 155-161

[45] A Pawlowski, M. Jansson, M. Sköld, M.E. Rottenberg and G. Källenius Tuberculosis and HIV Co-Infection. PLoS Pathogen 8(2), e1002464, 2012. Doi:10.1371/journal.ppat.10 02464

[46] C. Jaideep, M. Kumar and A.K. Khanna. Male breast tuberculosis. Postgraduate Medical Journal, 73, 428-429, 1997.

[47] S.P. Luh, K.J. Chang, J.H. Cheng, J.D. Hsu and C.S. Huang. Surgical treatment for primary mammary tuberculosis report of three octogenarian cases and review of literature. Breast Journal. 14, 311-2, 2008.

[48] E. Bouza and P. Munoz. Epidemiology of candidemia in intensive care units. International Journal of Antimicrobial Agents. 32, S87-91, 2008.

[49] S. Marol and M. Yücesoy. Molecular epidemiology of
Candida species isolated from clinical specimens of intensive care unit patients. Mycoses. 51, 40-9, 2008.

[50] M. McCullough, M. Jaber, A.W. Barrett, L. Bain, P.M. Speight and S.R. Porter. Oral yeast carriage correlates with presence of oral epithelial dysplasia. Oral Oncology, 38, 391-3, 2002

[51] A.W. Barret, V.J. Kinsmill, P.M. Speight. The frequency of fungal infection in biopsies of oral mucosal lesions. Oral Diseases. 4, 26-31, 1998

[52] P. Krogh, B. Hald, P. Holmstrup. Possible mycological etiology of oral mucosal cancer: catalytic potential of infecting Candida albicans and other yeasts in production of N-nitrosobenzylmethylamine. Carcinogenesis. 8, 1543-8, $1987 \mathrm{~b}$

[53] H.K. Singh, L. Bubendorf, M.J. Mihatsch, et al. Urine Cytology Findings of Polyomavirus Infections. In: Madame Curie Bioscience Database [Internet]. Austin (TX): Landes Bioscience; 2000-2013. Available from: http://www.ncbi.nl m.nih.gov/books/NBK6541/ Accessed 02/07/2016

[54] A.V. Kahan, D.V. Coleman and L.G. Koss. Activation of human polyomavirus infection-detection by cytologic technics. American Journal of Clinical Pathology. 74(3), 326-332, 1980

[55] B.A. Alexiev, P. Randhawa, M.E. Vazquez, G. Zeng, C. Luo, E. Ramos, C.B. Drachenberg, J.C. Papadimitriou. BK virus-associated urinary bladder carcinoma in transplant recipients: report of 2 cases, review of the literature, and proposed pathogenetic model. Human Pathology, 44(5), 908-917, 2013

[56] M. Cheesburgh District laboratory practice in tropical countries. Part 2, 2nd Ed. Cambridge University Press, New York. 2006. P.111-112

[57] Z. Mou, H.M. Muleme, D. Liu, P. Jia, I.B. Okwor, S. M. Kuriakose, S.M. Beverley, and J.E. Uzonna. Parasite-derived arginase influences secondary anti-Leishmania immunity by regulating PD-1-mediated CD4+ T cell exhaustion. Journal of Immunology. 190(7), 3380-3389, 2013. doi:10.4049/jim munol.1202537. 